\author{
M. Akat ${ }^{1}$, R. Kosker ${ }^{2}$, A. Sirma ${ }^{3}$ \\ ${ }^{1}$ Department of International Finance, Ozyegin University, Istanbul, Turkey \\ ${ }^{2}$ Department of Mathematical Engineering, Yildiz Technical University, Istanbul, Turkey \\ ${ }^{3}$ Department of Industrial Engineering, Halic University, Istanbul, Turkey \\ (E-mail: muzaffer.akat@ozyegin.edu.tr,kosker@yildiz.edu.tr, alisirma@halic.edu.tr)
}

\title{
On the numerical schemes for Langevin-type equations
}

\begin{abstract}
In this paper, a numerical approach is proposed based on the variation-of-constants formula for the numerical discretization Langevin-type equations. Linear and non-linear cases are treated separately. The proofs of convergence have been provided for the linear case, and the numerical implementation has been executed for the non-linear case. The order one convergence for the numerical scheme has been shown both theoretically and numerically. The stability of the numerical scheme has been shown numerically and depicted graphically.
\end{abstract}

Keywords: difference schemes, stochastic oscillators, Langevin equation, variation of constants

\section{Introduction}

In the beginning of the 20th century Paul Langevin discovered a very successful representation of the Brownian Motion [1]. This representation has been used as a fundamental building block, modified and generalized to analyze a large class of important stochastic processes. In simple terms, he applied the Newton's second law to a Brownian particle and obtained the differential equation that is known as the Langevin equation.

Due to its fundamental nature the generalized and modified versions of the Langevin equation has been used for modeling particle movements in so many different fields. [2] shows how it could be utilized in the statistical mechanics . Kubo introduces a generalized version of the equation for different applications [3,4]. [5] introduces a structure of energetics into the stochastic system described by the Langevin equation and applies it in the thermodynamics context. [6] shows that how the HeisenbergLangevin equation can be used to derive a Schrödinger equation for a Brownian particle interacting with a thermal environment. [7] used an approximate time-evolution equation of the Langevin type in modeling chemically reacting systems. [8] applies the Langevin equation in a stochastic control problem. [9] numerically investigates the Brownian motion of particles in a fluid with inhomogeneous temperature field.

In this study, a modified version of the Langevin equation has been studied from a numerical perspective. The convergence rate analysis of numerical schemes designed for these type of equations have been examined thoroughly in the literature. For a general treatment of numerical solutions of stochastic differential equations the reader is referred to [10].

[11] considers similar stochastic differential equations and analyzes the convergence rate of a numerical method where the approximation of the drift coefficient is done by the local linearization method and the diffusion coefficient by the Euler method. It is shown that order one convergence is obtained which is in line with the results obtained in this paper. The order of convergence of the Euler method for neutral stochastic functional differential equations has been studied in [12] where also similar order of convergence has been achieved. Convergence performance of different numerical integrators have been discussed in $[13,14]$ specifically for the Langevin-type equations, and weak convergence of order one has been obtained.

[15] considered the same Langevin-type equation

$$
\ddot{X}_{t}=X_{t}-X_{t}^{3}-\nu \dot{X}_{t}+\sigma \dot{W}_{t}
$$


and approached to solve the equation by putting it into the form of

$$
\ddot{X}_{t}+\nu \dot{X}_{t}=X_{t}-X_{t}^{3}+\sigma \dot{W}_{t}
$$

[15] obtained numerical schemes for the approximation of the solution (2). While discretizing the integral he used the trapezoidal rule. The numerical schemes are obtained by the variation-of-constants formula, however, no analysis of convergence of the numerical schemes has been given.

In this study, equation (1) has been considered under the form of

$$
\ddot{X}_{t}+\nu \dot{X}_{t}-X_{t}=-X_{t}^{3}+\sigma \dot{W}_{t}
$$

Therefore, slightly different numerical schemes are obtained for the approximation of the solution of the equation (1). In addition to this, while discretizing the integral the left hand rule has been used as opposed to the trapezoidal rule. The results in the existing literature have been obtained but in an easier and more straight forward way. Furthermore, higher order of convergence rates have been established both for one step convergence and general $n$ step convergence.

The organization of the paper is as follows. In section 2, an explicit numerical scheme has been derived for equation (1). The convergence analysis has been worked out in detail and order $h$ convergence has been proved. In section 3 , the theoretical results obtained in the previous section have been verified and a further stability analysis has been carried out. Finally, in section 4, the results are summarized and the paper is concluded.

\section{Numerical schemes for Langevin-type equations}

Now, let us consider the oscillator with cubic restoring force and additive noise from [15].

$$
\ddot{X}_{t}=X_{t}-X_{t}^{3}-\nu \dot{X}_{t}+\sigma \dot{W}_{t} .
$$

Let us consider the Langevin-type Eq.(4) in the form

$$
\ddot{X}_{t}+\nu \dot{X}_{t}-X_{t}=-X_{t}^{3}+\sigma \dot{W}_{t} .
$$

Let us write Eq.(5) as a system of first-order Ito stochastic differential equations

$$
\left(\begin{array}{c}
d X_{t} \\
d Y_{t}
\end{array}\right)=\left(\begin{array}{cc}
0 & 1 \\
1 & -\nu
\end{array}\right)\left(\begin{array}{c}
X_{t} \\
Y_{t}
\end{array}\right) d t+\left(\begin{array}{c}
0 \\
-X_{t}^{3}+\sigma d W_{t}
\end{array}\right)
$$

Let us find the unique solution of Eq.(6) using the method of variation of constants formula. Namely, first let us find the solution of homogeneous part. For this consider the matrix

$$
A=\left(\begin{array}{cc}
0 & 1 \\
1 & -\nu
\end{array}\right)
$$

The eigenvalues of the matrix $A$ are $r=\frac{-\nu+\sqrt{\nu^{2}+4}}{2}$ and $-r-\nu$, with the corresponding eigenvectors $(1, r)^{T}$ and $(1,-r-\nu)^{T}$, respectively. Using these information, we can write the matrix $A$ as a Jordan canonic form to write the exponential matrix $e^{A t}$ as

$$
e^{A t}=\left(\begin{array}{cc}
1 & 1 \\
r & -r-\nu
\end{array}\right)\left(\begin{array}{cc}
e^{r t} & 0 \\
0 & e^{(-r-\nu) t}
\end{array}\right) \frac{1}{-2 r-\nu}\left(\begin{array}{cc}
-r-\nu & -1 \\
-r & 1
\end{array}\right) .
$$

From here the solution of homogeneous part is found as

$$
X_{t}=\frac{1}{2 r+\nu}\left(\alpha_{11}(t) X_{0}+\alpha_{12}(t) Y_{0}\right)
$$




$$
Y_{t}=\frac{1}{2 r+\nu}\left(\alpha_{21}(t) X_{0}+\alpha_{22}(t) Y_{0}\right)
$$

where

$$
\begin{gathered}
\alpha_{11}(t)=(r+\nu) e^{r t}+r e^{(-r-\nu) t}, \alpha_{12}(t)=e^{r t}-e^{(-r-\nu) t}, \\
\alpha_{21}(t)=r(r+\nu) e^{r t}-r(r+\nu) e^{(-r-\nu) t} \text { and } \alpha_{22}(t)=r e^{r t}+(r+\nu) e^{(-r-\nu) t} .
\end{gathered}
$$

Therefore, by the variation of constants formula the solution of the non-homogeneous Eq.(6) is

$$
\left(\begin{array}{c}
X_{t} \\
Y_{t}
\end{array}\right)=e^{A t}\left(\begin{array}{c}
X_{0} \\
Y_{0}
\end{array}\right)+\int_{0}^{t} e^{A(t-s)}\left(\begin{array}{c}
0 \\
-X_{s}^{3}+\sigma d W_{s}
\end{array}\right) d s
$$

Hence,

$$
\begin{aligned}
& X_{t}=\frac{1}{2 r+\nu}\left(\alpha_{11}(t) X_{0}+\alpha_{12}(t) Y_{0}\right)+\frac{1}{2 r+\nu} \int_{0}^{t} \alpha_{12}(t-s)\left(-X_{s}^{3}+\sigma \dot{W}_{s}\right) d s, \\
& Y_{t}=\frac{1}{2 r+\nu}\left(\alpha_{21}(t) X_{0}+\alpha_{22}(t) Y_{0}\right)+\frac{1}{2 r+\nu} \int_{0}^{t} \alpha_{22}(t-s)\left(-X_{s}^{3}+\sigma \dot{W}_{s}\right) d s .
\end{aligned}
$$

Using the fact that $e^{A t} e^{A s}=e^{A(t+s)}$, discretizing the integrals with the left hand rule gives the following explicit numerical scheme

$$
\begin{aligned}
& X_{n+1}=\frac{1}{2 r+\nu}\left(\alpha_{11}(h) X_{n}+\alpha_{12}(h) Y_{n}\right)-\frac{h}{2 r+\nu} \alpha_{12}(h) X_{n}^{3}+\frac{\sigma}{2 r+\nu} \alpha_{12}(h) \Delta W_{n}, \\
& Y_{n+1}=\frac{1}{2 r+\nu}\left(\alpha_{21}(h) X_{n}+\alpha_{22}(h) Y_{n}\right)-\frac{h}{2 r+\nu} \alpha_{22}(h) X_{n}^{3}+\frac{\sigma}{2 r+\nu} \alpha_{22}(h) \Delta W_{n} .
\end{aligned}
$$

It is clearly seen that the solution of linear part of non-homogeneous equation is

$$
\begin{aligned}
& X_{t}=\frac{1}{2 r+\nu}\left(\alpha_{11}(t) X_{0}+\alpha_{12}(t) Y_{0}\right)-\frac{\sigma}{2 r+\nu} \int_{0}^{t} \alpha_{12}(t-s) d W_{s}, \\
& Y_{t}=\frac{1}{2 r+\nu}\left(\alpha_{21}(t) X_{0}+\alpha_{22}(t) Y_{0}\right)-\frac{\sigma}{2 r+\nu} \int_{0}^{t} \alpha_{22}(t-s) d W_{s},
\end{aligned}
$$

and discretization of linear part is

$$
\begin{aligned}
& X_{n+1}=\frac{1}{2 r+\nu}\left(\alpha_{11}(h) X_{n}+\alpha_{12}(h) Y_{n}\right)+\frac{\sigma}{2 r+\nu} \alpha_{12}(h) \Delta W_{n}, \\
& Y_{n+1}=\frac{1}{2 r+\nu}\left(\alpha_{21}(h) X_{n}+\alpha_{22}(h) Y_{n}\right)+\frac{\sigma}{2 r+\nu} \alpha_{22}(h) \Delta W_{n} .
\end{aligned}
$$

Lemma 1. For the numerical solution of linear first order system of differential equation

$$
\left(\begin{array}{c}
d X_{t} \\
d Y_{t}
\end{array}\right)=\left(\begin{array}{cc}
0 & 1 \\
-1 & \nu
\end{array}\right)\left(\begin{array}{c}
X_{t} \\
Y_{t}
\end{array}\right) d t+\left(\begin{array}{c}
0 \\
\sigma d W_{t}
\end{array}\right)
$$

consider numerical scheme (11) and (12). Then, the mean square errors after one step of the numerical schemes satisfy the following estimates:

$$
\begin{gathered}
\left(E\left[\left|X_{1}-X_{h}\right|^{2}\right]\right)^{1 / 2} \leq C_{1}(T) \sigma h^{3 / 2}, \\
\left(E\left[\left|Y_{1}-Y_{h}\right|^{2}\right]\right)^{1 / 2} \leq C_{2}(T) \sigma h^{3 / 2},
\end{gathered}
$$

where the constants $C_{1}(T)$ and $C_{2}(T)$ are independent of $\sigma$ and $h$, but depend on $T$. Here, $X_{h}, Y_{h}$ denote the exact solution after a time $h$ and $X_{1}, Y_{1}$ denote the numerical solution after one step. That is the local errors are of order $3 / 2$ uniformly. 
Proof. By definition,

$$
E\left[\left|X_{1}-X_{h}\right|^{2}\right]=\left(\frac{\sigma}{2 r+\nu}\right)^{2} E\left(\int_{0}^{h}\left[\left(\alpha_{12}(h)-\alpha_{12}(h-s)\right) d w_{s}\right]\right)^{2}
$$

but using Itô isometry, we get

$$
=\left(\frac{\sigma}{2 r+\nu}\right)^{2} \int_{0}^{h}\left[\alpha_{12}(h)-\alpha_{12}(h-s)\right]^{2} d s .
$$

Then by the mean value theorem, we have

$$
=\left(\frac{\sigma}{2 r+\nu}\right)^{2} \int_{0}^{h}\left[\alpha_{12}^{\prime}(\xi(s))(h-(h-s))\right]^{2} d s
$$

for some $h-s<\xi(s)<h$.

Since we have $\left|\alpha_{12}^{\prime}(\xi(s))\right|=\left|r e^{r \xi}+(r+\nu) e^{(-r-\nu) \xi}\right| \leq\left|r e^{r \xi}+(r+\nu) e^{r \xi}\right| \leq\left|(2 r+\nu) e^{r h}\right|$ then we get

$$
\left(E\left[\left|X_{1}-X_{h}\right|^{2}\right]\right) \leq \sigma^{2} e^{2 r h} h^{3} / 3 \leq \sigma^{2} e^{2 r T} h^{3} / 3 .
$$

Hence, we have

$$
\left(E\left[\left|X_{1}-X_{h}\right|^{2}\right]\right)^{1 / 2} \leq \sigma C_{1}(T) h^{3 / 2}
$$

for some positive constant $C_{1}(T)$ does not depend on $h$ and $\sigma$, but depends on $T$.

The mean square error after one step for numerical scheme for velocity is

$$
E\left[\left|Y_{1}-Y_{h}\right|^{2}\right]=\left(\frac{\sigma}{2 r+\nu}\right)^{2} E\left(\int_{0}^{h}\left[\left(\alpha_{22}(h)-\alpha_{22}(h-s)\right) d w_{s}\right]\right)^{2} .
$$

But using Itô isometry, we get

$$
=\left(\frac{\sigma}{2 r+\nu}\right)^{2} \int_{0}^{h}\left[\alpha_{22}(h)-\alpha_{22}(h-s)\right]^{2} d s .
$$

Then by the mean value theorem, we have

$$
=\left(\frac{\sigma}{2 r+\nu}\right)^{2} \int_{0}^{h}\left[\alpha_{22}^{\prime}(\xi(s))(h-(h-s))\right]^{2} d s
$$

for some $h-s<\xi<h$.

Since $\left|\alpha_{22}^{\prime}(\xi(s))\right|=\left|r^{2} e^{r \xi(s)}-(r+\nu)^{2} e^{(-r-\nu) \xi(s)}\right| \leq\left|r^{2} e^{r h}-(r+\nu)^{2} e^{(-r-\nu) h}\right| \leq r^{2} e^{r h} \leq(2 r+\nu) e^{r h}$ and since $\alpha_{22}^{\prime}(\xi(s))$ is an increasing function, then we have

$$
\left(E\left[\left|Y_{1}-Y_{h}\right|^{2}\right]\right)^{1 / 2} \leq \sigma e^{r h} h^{3 / 2} / \sqrt{3} \leq \sigma C_{2}(T) h^{3 / 2},
$$

for some positive constant $C_{2}(T)$ does not depend on $h$ and $\sigma$, but depends on $T$.

Corollary 1. Let $c_{p}$ be a solution of the equation $e^{x} x^{p}=1,0<p<1.5$. If we take in Lemma 1 the step size $h$ with $h<\left(c_{p}\right)^{1 / p} / 2 r$ then we have the mean square errors after one step of the numerical schemes satisfy the following estimates

$$
\begin{gathered}
\left(E\left[\left|X_{1}-X_{h}\right|^{2}\right]\right)^{1 / 2} \leq C_{1} \sigma h^{(3-p) / 2}, \\
\left(E\left[\left|Y_{1}-Y_{h}\right|^{2}\right]\right)^{1 / 2} \leq C_{2} \sigma h^{(3-p) / 2}
\end{gathered}
$$


where the constants $C_{1}$ and $C_{2}$ are independent of $\sigma, h$ and $T$. If we take for example $p=1.2$, then we get the case $c_{1.2}=0.6043$. Hence, for any $h<0.6572 / 2 r$, the mean square errors after one step of the numerical schemes satisfy

$$
\begin{gathered}
\left(E\left[\left|X_{1}-X_{h}\right|^{2}\right]\right)^{1 / 2} \leq C_{1} \sigma h^{0.9}, \\
\left(E\left[\left|Y_{1}-Y_{h}\right|^{2}\right]\right)^{1 / 2} \leq C_{2} \sigma h^{0.9} .
\end{gathered}
$$

To show general mean square errors at time $\mathrm{T}$, we need to obtain the following estimates.

Lemma 2. a) We have $E\left|d_{n}^{X}\right|=E\left|d_{n}^{Y}\right|=0$.

b) We have $E\left[\left(d_{n}^{X}\right)^{2}\right]=O\left(h^{3}\right), E\left[\left(d_{n}^{Y}\right)^{2}\right]=O\left(h^{3}\right)$ and $E\left[\left|d_{n}^{X} d_{n}^{Y}\right|\right]=O\left(h^{3}\right)$,

where

$$
d_{n}^{X}=\frac{\sigma}{2 r+\nu}\left(\int_{t_{n}}^{t_{n+1}} \alpha_{12}\left(t_{n+1}-s\right) d w_{s}-\alpha_{12}(h) \Delta W_{n}\right)
$$

and

$$
d_{n}^{Y}=\frac{\sigma}{2 r+\nu}\left(\int_{t_{n}}^{t_{n+1}} \alpha_{22}\left(t_{n+1}-s\right) d w_{s}-\alpha_{22}(h) \Delta W_{n}\right)
$$

Proof.

a) Since the Itô stochastic integral has expectation zero, the estimates $E\left|d_{n}^{X}\right|=E\left|d_{n}^{Y}\right|=0$ follow.

b) By definition

$$
E\left(d_{n}^{X}\right)^{2}=\left(\frac{\sigma}{2 r+\nu}\right)^{2} E\left(\int_{t_{n}}^{t_{n+1}}\left(\alpha_{12}\left(t_{n+1}-s\right)-\alpha_{12}(h)\right) d W_{s}\right)^{2} .
$$

Then, by the Itô's isometry we have

$$
=\left(\frac{\sigma}{2 r+\nu}\right)^{2} \int_{t_{n}}^{t_{n+1}}\left(\alpha_{12}\left(t_{n+1}-s\right)-\alpha_{12}(h)\right)^{2} d s .
$$

But by the mean value theorem

$$
=\left(\frac{\sigma}{2 r+\nu}\right)^{2} \int_{t_{n}}^{t_{n+1}}((n+1) h-s-h)^{2}\left(\alpha_{12}^{\prime}(\xi(s))\right)^{2} d s,
$$

for some $t_{n+1}-s<\xi(s)<h$, for the differentiable function $\left.\alpha_{12}(x)=e^{r x}-e^{(-r-\nu) x}\right)$ we have $\left|\alpha_{12}^{\prime}(\xi(s))\right| \leq \leq(2 r+\nu) e^{r h}$. Then

$$
\begin{gathered}
\leq\left(\frac{\sigma}{2 r+\nu}\right)^{2} \int_{t_{n}}^{t_{n+1}}(n h-s)^{2}\left((2 r+\nu) e^{r h}\right)^{2} d s \\
=\sigma^{2} e^{2 r h} \int_{t_{n}}^{t_{n+1}}\left(n^{2} h^{2}-2 n h s+s^{2}\right) d s=\sigma^{2} e^{2 r T} h^{3} / 3,
\end{gathered}
$$

for any $h<c_{0} / 2 r$ since $\int_{t_{n}}^{t_{n+1}}\left(n^{2} h^{2}-2 n h s+s^{2}\right) d s=h^{3} / 3$.

In the same manner, by definition

$$
E\left(d_{n}^{Y}\right)^{2}=\left(\frac{\sigma}{2 r+\nu}\right)^{2} E\left(\int_{t_{n}}^{t_{n+1}}\left(\alpha_{22}\left(t_{n+1}-s\right)-\alpha_{22}(h)\right) d W_{s}\right)^{2} .
$$

then, by the Itô's isometry we have

$$
=\left(\frac{\sigma}{2 r+\nu}\right)^{2} \int_{t_{n}}^{t_{n+1}}\left(\alpha_{22}\left(t_{n+1}-s\right)-\alpha_{22}(h)\right)^{2} d s
$$


But by the mean value theorem

$$
=\left(\frac{\sigma}{2 r+\nu}\right)^{2} \int_{t_{n}}^{t_{n+1}}((n+1) h-s-h)^{2}\left(\alpha_{22}^{\prime}(\xi(s))\right)^{2} d s,
$$

for some $t_{n+1}-s<\xi<h$ and for the differentiable function $\left.\alpha_{22}(x)=r e^{r x}+(r+\nu) e^{(-r-\nu) x}\right)$. Since the function $\left|\alpha_{22}^{\prime}(x)\right|$ is an increasing function, $\left.\alpha_{22}^{\prime}(\xi(s)) \leq r^{2} e^{r h}-(r+\nu)^{2} e^{(-r-\nu) h} \leq r^{2} e^{r h} \leq(2 r+\nu) e^{r h}\right)$. Then

$$
\begin{gathered}
\leq\left(\frac{\sigma}{2 r+\nu}\right)^{2} \int_{t_{n}}^{t_{n+1}}(n h-s)^{2}\left((2 r+\nu) e^{r h}\right)^{2} d s \\
=\sigma^{2} e^{2 r h} \int_{t_{n}}^{t_{n+1}}\left(n^{2} h^{2}-2 n h s+s^{2}\right) d s=\sigma^{2} e^{2 r T} h^{3} / 3 .
\end{gathered}
$$

Now, let us find an estimate for $\left|d_{n}^{X} d_{n}^{Y}\right|$. But by the fact that expectation of product of independent increments is zero, we have

$$
\left|d_{n}^{X} d_{n}^{Y}\right| \leq\left(\frac{\sigma}{2 r+\nu}\right)^{2} \int_{t_{n}}^{t_{n+1}}\left(\alpha_{12}\left(t_{n+1}-s\right)-\alpha_{12}(h)\right)\left(\alpha_{22}\left(t_{n+1}-s\right)-\alpha_{22}(h)\right) d s .
$$

But by the mean value theorem, we obtain

$$
\left|d_{n}^{X} d_{n}^{Y}\right| \leq\left(\frac{\sigma}{2 r+\nu}\right)^{2} \int_{t_{n}}^{t_{n+1}}((n+1) h-s-h)^{2}\left|\alpha_{12}^{\prime}(\psi(s)) \| \alpha_{22}^{\prime}(\xi(s))\right| d s
$$

for some $t_{n+1}-s<\psi(s)<h$ and $t_{n+1}-s<\xi(s)<h$. Hence,

$$
\begin{aligned}
& \leq\left(\frac{\sigma}{2 r+\nu}\right)^{2} \int_{t_{n}}^{t_{n+1}}(n h-s)^{2}\left((2 r+\nu) e^{r h}\right)(2 r+\nu) e^{r h} d s \\
& =r \sigma^{2} e^{2 r h} \int_{t_{n}}^{t_{n+1}}\left(n^{2} h^{2}-2 n h s+s^{2}\right) d s=\sigma^{2} e^{2 r T} h^{3} / 3 .
\end{aligned}
$$

Corollary 2. Let the positive real numbers $p$ and $c_{p}$ be as in Corollary 1 . If we take in Lemma 2 the step size $h$ with $h<\left(c_{p}\right)^{1 / p} / 2 r$, then

a) $E\left[\left(d_{n}^{X}\right)^{2}\right]=O\left(h^{3-p}\right), E\left[\left(d_{n}^{Y}\right)^{2}\right]=O\left(h^{3-p}\right)$ and $E\left[\left|d_{n}^{X} d_{n}^{Y}\right|\right]=O\left(h^{3-p}\right)$, where the upper bounds for the estimates do not depend on $\sigma, h$, and $T$. If we take, for example $p=1.2$, then we get the case $c_{1.2}=0.6043$. Hence, for any $h<0.6572 / 2 r$

b) $E\left[\left(d_{n}^{X}\right)^{2}\right]=O\left(h^{1.8}\right), E\left[\left(d_{n}^{Y}\right)^{2}\right]=O\left(h^{1.8}\right)$ and $E\left[\left|d_{n}^{X} d_{n}^{Y}\right|\right]=O\left(h^{1.8}\right)$.

We now indicate the global mean-square error of the stochastic exponential integrators (11) and (12).

Theorem 1. Consider the numerical solution of (13), the method (11) and (12). Then, the meansquare errors of the numerical scheme satisfy

a) $\left(E\left|X_{n}-X_{t_{n}}\right|^{2}\right)^{1 / 2} \leq C_{3}(T) h$,

b) $\left(E\left|Y_{n}-Y_{t_{n}}\right|^{2}\right)^{1 / 2} \leq C_{4}(T) h$,

for some constants $C_{3}(T)$ and $C_{4}(T)$.

Proof. The recursive relation for the solution of linear part is

$$
\left(\begin{array}{c}
X_{t_{n+1}} \\
Y_{t_{n+1}}
\end{array}\right)=e^{A h}\left(\begin{array}{c}
X_{t_{n}} \\
Y_{t_{n}}
\end{array}\right)+\int_{t_{n}}^{t_{n+1}} e^{A\left(t_{n+1}-s\right)}\left(\begin{array}{c}
0 \\
\sigma \dot{W}_{s}
\end{array}\right) d s
$$

Using equations (11) and (12), we have

$$
E_{n+1}=e^{A h} E_{n}+d_{n}
$$


where $E_{n}=\left(\begin{array}{c}e_{n}^{X} \\ e_{n}^{Y}\end{array}\right)=\left(\begin{array}{c}X_{t_{n}}-X_{n} \\ Y_{t_{n}}-Y_{n}\end{array}\right)$ and $d_{n}=\left(\begin{array}{c}d_{n}^{X} \\ d_{n}^{Y}\end{array}\right)$. Using the mathematical induction, we obtain the formula

$$
E_{n+1}=e^{A(n+1) h} E_{0}+\sum_{j=0}^{n} e^{A(n-j) h} d_{n}=\sum_{j=0}^{n} e^{A(n-j) h} d_{j},
$$

since $E_{0}=\overrightarrow{0}$. Hence,

$$
\begin{gathered}
E\left[\left(e_{n+1}^{X}\right)^{2}\right]=\left(\frac{1}{2 r+\nu}\right)^{2} E\left[\sum_{j=0}^{n}\left(\alpha_{11}((n-j) h) d_{j}^{X}+\alpha_{12}((n-j) h) d_{j}^{Y}\right)\right]^{2} \\
=\left(\frac{1}{2 r+\nu}\right)^{2} E \sum_{j=0}^{n} \sum_{i=0}^{n}\left(\alpha_{11}((n-j) h) d_{j}^{X}+\alpha_{12}((n-j) h) d_{j}^{Y}\right)\left(\alpha_{11}((n-i) h) d_{i}^{X}+\alpha_{12}((n-i) h) d_{i}^{Y}\right)
\end{gathered}
$$

since expectation of product of independent increments is zero, we have

$$
\begin{gathered}
=\left(\frac{1}{2 r+\nu}\right)^{2} \sum_{j=0}^{n}\left(\left(\alpha_{11}((n-j) h)\right)^{2} E\left(\left(d_{j}^{X}\right)^{2}\right)+\left(\alpha_{12}((n-j) h)\right)^{2} E\left(\left(d_{j}^{Y}\right)^{2}\right)\right) \\
+2\left(\frac{1}{2 r+\nu}\right)^{2} \sum_{j=0}^{n}\left(\alpha_{11}((n-j) h) \alpha_{12}((n-j) h) E\left(d_{j}^{X} d_{j}^{Y}\right)\right) \\
=\left(\frac{1}{2 r+\nu}\right)^{2} \sum_{j=0}^{n}\left(\alpha_{11}((n-j) h)+\alpha_{12}((n-j) h)\right)^{2} O\left(h^{3}\right) \\
=\left(\frac{1}{2 r+\nu}\right)^{2} \sum_{j=0}^{n}\left((r+\nu) e^{r j h}+r e^{(-r-\nu) j h}+e^{r j h}-e^{(-r-\nu) j h}\right)^{2} O\left(h^{3}\right) \\
\leq\left(\frac{1}{2 r+\nu}\right)^{2} \sum_{j=0}^{n}\left((2 r+\nu+1) e^{r j h}\right)^{2} O\left(h^{3}\right) \\
\leq\left(\frac{2 r+\nu+1}{2 r+\nu}\right)^{2} T e^{2 r T} O\left(h^{2}\right) .
\end{gathered}
$$

Similarly, we get

$$
\begin{gathered}
E\left[\left(e_{n+1}^{Y}\right)^{2}\right]=\left(\frac{1}{2 r+\nu}\right)^{2} E\left[\sum_{j=0}^{n}\left(\alpha_{21}((n-j) h) d_{j}^{X}+\alpha_{22}((n-j) h) d_{j}^{Y}\right)\right]^{2} \\
=\left(\frac{1}{2 r+\nu}\right)^{2} \sum_{j=0}^{n}\left(\alpha_{21}((n-j) h)+\alpha_{22}((n-j) h)\right)^{2} O\left(h^{3}\right) \\
=\left(\frac{1}{2 r+\nu}\right)^{2} \sum_{j=0}^{n}\left(r(r+\nu) e^{r j h}-r(r+\nu) e^{(-r-\nu) j h}+r e^{r j h}+(r+\nu) e^{(-r-\nu) j h}\right)^{2} O\left(h^{3}\right) \\
=\left(\frac{1}{2 r+\nu}\right)^{2} \sum_{j=0}^{n}\left(r(r+\nu+1) e^{r j h}+(1-r)(r+\nu) e^{(-r-\nu) j h}\right)^{2} O\left(h^{3}\right)
\end{gathered}
$$


since $0<r<1$, we have

$$
\leq\left(\frac{1}{2 r+\nu}\right)^{2} \sum_{j=0}^{n}\left((r(r+\nu+1)+(1-r)(r+\nu)) e^{r j h}\right)^{2} O\left(h^{3}\right) \leq T e^{2 r T} O\left(h^{2}\right) .
$$

This completes the proof of the theorem.

Corollary 3. Consider the numerical solution of (13), the method (11) and (12). Let $1<p<1.5$ and let the positive real number $c_{p}$ be as in Corollary 1. In Theorem 1 if we take the step size $h$ with $h<\left(c_{p}\right)^{1 / p} /(2 r j)$ for any $j=1,2,3, \ldots, n$ and using Corollary 2, therefore the mean-square errors of the numerical scheme satisfy the convergence estimates

a) $\left(E\left|X_{n}-X_{t_{n}}\right|^{2}\right)^{1 / 2} \leq C_{3} h^{(3-2 p) / 2}$

b) $\left(E\left|Y_{n}-Y_{t_{n}}\right|^{2}\right)^{1 / 2} \leq C_{4} h^{(3-2 p) / 2}$

for some constants $C_{3}$ and $C_{4}$ independent of $T$.

Proof. By following the proof of Theorem 1, we have

$$
\begin{gathered}
E\left[\left(e_{n+1}^{X}\right)^{2}\right] \\
\leq\left(\frac{1}{2 r+\nu}\right)^{2} \sum_{j=0}^{n}(2 r+\nu+1)^{2} e^{2 r j h} O\left(h^{3-p}\right) \leq\left(\frac{2 r+\nu+1}{2 r+\nu}\right)^{2} \frac{1}{(2 r)^{p}} O\left(h^{3-2 p}\right)\left(1+\sum_{j=1}^{n} \frac{1}{j^{p}}\right) .
\end{gathered}
$$

Since the infinite series $\sum_{j} \frac{1}{j^{p}}$ converges for $p>1$, we have

$$
\left(E\left|X_{n}-X_{t_{n}}\right|^{2}\right)^{1 / 2} \leq C_{3} h^{(3-2 p) / 2} .
$$

But this estimate is independent of $T$.

Estimate b) for the velocity component is obtained in a similar way.

\section{Numerical Results}

For the comparison of the numeric solution of the difference equation and the analytical solution of the differential equation, the error terms are computed by the following formulation:

$$
E_{h}=\frac{1}{N_{\text {sim }}}\left(\sum_{j=1}^{N_{\text {sim }}}\left(X_{n}-X_{t_{n}}\right)^{2}\right)^{1 / 2}
$$

Maintaining the same notation that has been used in the second section, we represent the analytical solution of system of equations (6) by $X_{t_{n}}$, and numerical solutions of the problem based on the equations (11)-(12) by $X_{n}$. The error terms are recorded for various values of $h$, i.e. size of the step in time. The results are shown in the Table 1 for $h=0.1, h=0.01, h=0.001$ and $h=0.0001$, respectively. In all of these numerical experiments, the number of simulations $N_{\text {sim }}$ is kept constant at 10,000 . Hence, each numerical problem has been solved based on 10,000 different sample paths for the process of Standard Brownian motion, $W_{t}$. As one could easily see from Table 1 and the way that the error is computed in equation (18) the convergence between the numerical and the analytical solutions is measured in the sense of pointwise convergence with respect to the time variable. Each row in the table measures the difference between the numerical and the analytical solution for a specific time point between $t=0$ and $t=1$. Finally, for each sample path this difference is computed, squared, summed, square rooted and averaged based on the number of simulations used, which is 10,000, to arrive at the final value of the error term. This final step is the typical way of computing the error for Monte Carlo Simulation applications which is often called in the literature as the root mean square error. 
Comparison of the errors for the approximate solution of problem

\begin{tabular}{ccccc}
\hline Point in Time/Step Size & $h=0.1$ & $h=0.01$ & $h=0.001$ & $h=0.0001$ \\
\hline $\mathrm{t}=0.1$ & $6.3198 \mathrm{e}-04$ & $7.4114 \mathrm{e}-05$ & $1.0097 \mathrm{e}-06$ & $2.9488 \mathrm{e}-07$ \\
$\mathrm{t}=0.2$ & 0.0022 & $6.8840 \mathrm{e}-04$ & $1.1159 \mathrm{e}-04$ & $5.0846 \mathrm{e}-05$ \\
$\mathrm{t}=0.3$ & 0.0038 & $4.7510 \mathrm{e}-04$ & $5.1366 \mathrm{e}-04$ & $6.6956 \mathrm{e}-05$ \\
$\mathrm{t}=0.4$ & 0.0123 & 0.0025 & $1.9910 \mathrm{e}-04$ & $2.8405 \mathrm{e}-05$ \\
$\mathrm{t}=0.5$ & 0.0120 & 0.0013 & $2.7540 \mathrm{e}-04$ & $2.2375 \mathrm{e}-05$ \\
$\mathrm{t}=0.6$ & 0.0161 & 0.0064 & 0.0017 & $8.1783 \mathrm{e}-04$ \\
$\mathrm{t}=0.7$ & 0.0244 & 0.0061 & $6.4270 \mathrm{e}-04$ & $9.8445 \mathrm{e}-05$ \\
$\mathrm{t}=0.8$ & 0.0511 & 0.0093 & 0.0019 & $9.1302 \mathrm{e}-04$ \\
$\mathrm{t}=0.9$ & 0.0616 & 0.0157 & 0.0077 & 0.0031 \\
$\mathrm{t}=1.0$ & 0.0829 & 0.0033 & 0.0012 & $5.4713 \mathrm{e}-04$ \\
\hline
\end{tabular}

Some of the rows in Table 1 are highlighted in order to emphasize the order one convergence which is theoretically proved in Theorem 1. It is clear that for each cell in the Table the number of steps is multiplied by 10, hence the size of the step is divided by 10. It is expected that the error term goes down by a factor of 10 as one goes from left to right on each row. If the first row is considered, highlighted light blue, roughly the error terms are divided by 10 at every step going from left to right. If one carefully looks that that first highlighted row, he would see that every step there is one more digit that is 0 . First row corresponds to the error term at $t=0.1$. Similar observations can also be made about the other rows, especially on the pink highlighted row that corresponds to $t=0.6$ and the yellow highlighted row which corresponds to $t=1$. Figure 1 shows the behaviour of $E\left[X_{t}^{2}\right]$ computed along 10,000 sample paths for a step size $h=0.001$ on the time interval $[0,100]$ along the numerical solution given by the previous section.
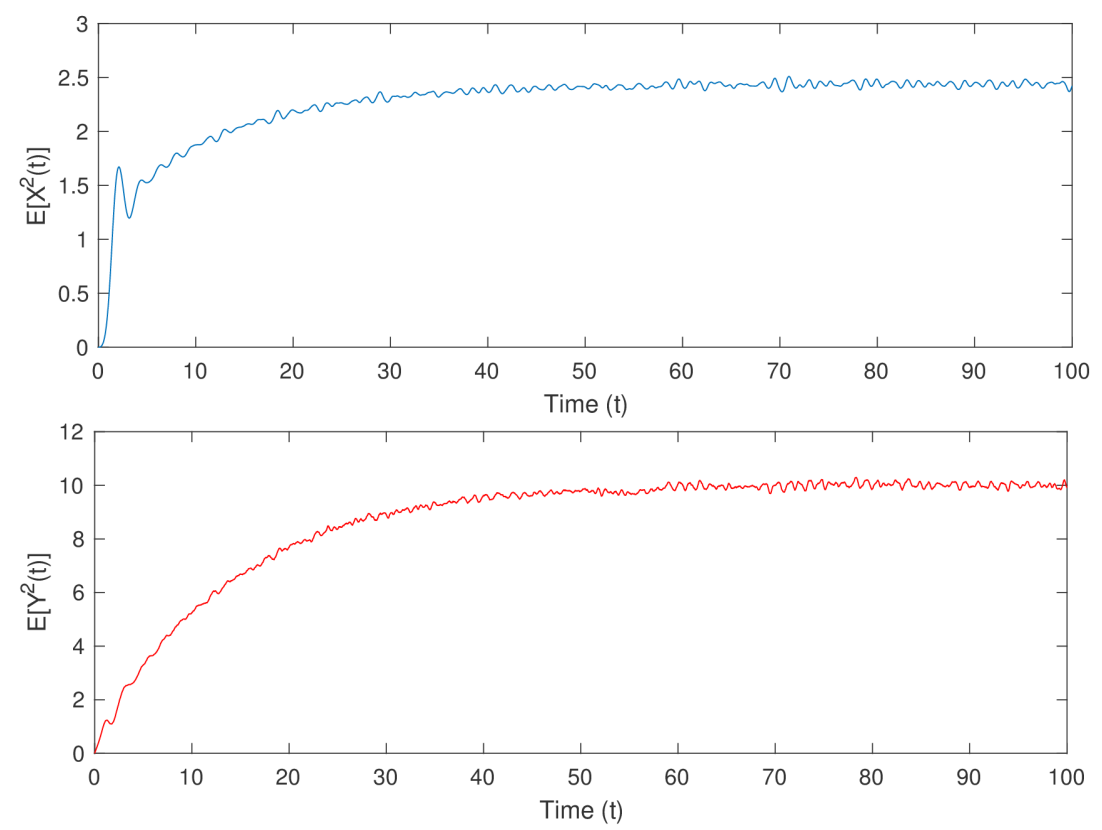

Figure 1. The convergence of expected value of the squared position and velocity functions

As $T \rightarrow \infty$, the numerical solution converges to the limit value 2.44 , and the velocity converges to the value 9.92. [15] does the same numerical exercise with the same model parameters and initial conditions. [15] obtains a very similar result for the solution. Here, the numerical experiment has been 
extended to the velocity also. For further details on the physical interpretation of this result, the reader is referred to look at [16].

At least, this numerical experiment can be thought as a test of stability. In Table 1 error terms beyond $t=1$ is not reported. One could be interested in the question that what happens to the numerical solution as the time grows. This is a partial answer to that question that the proposed numerical scheme is stable.
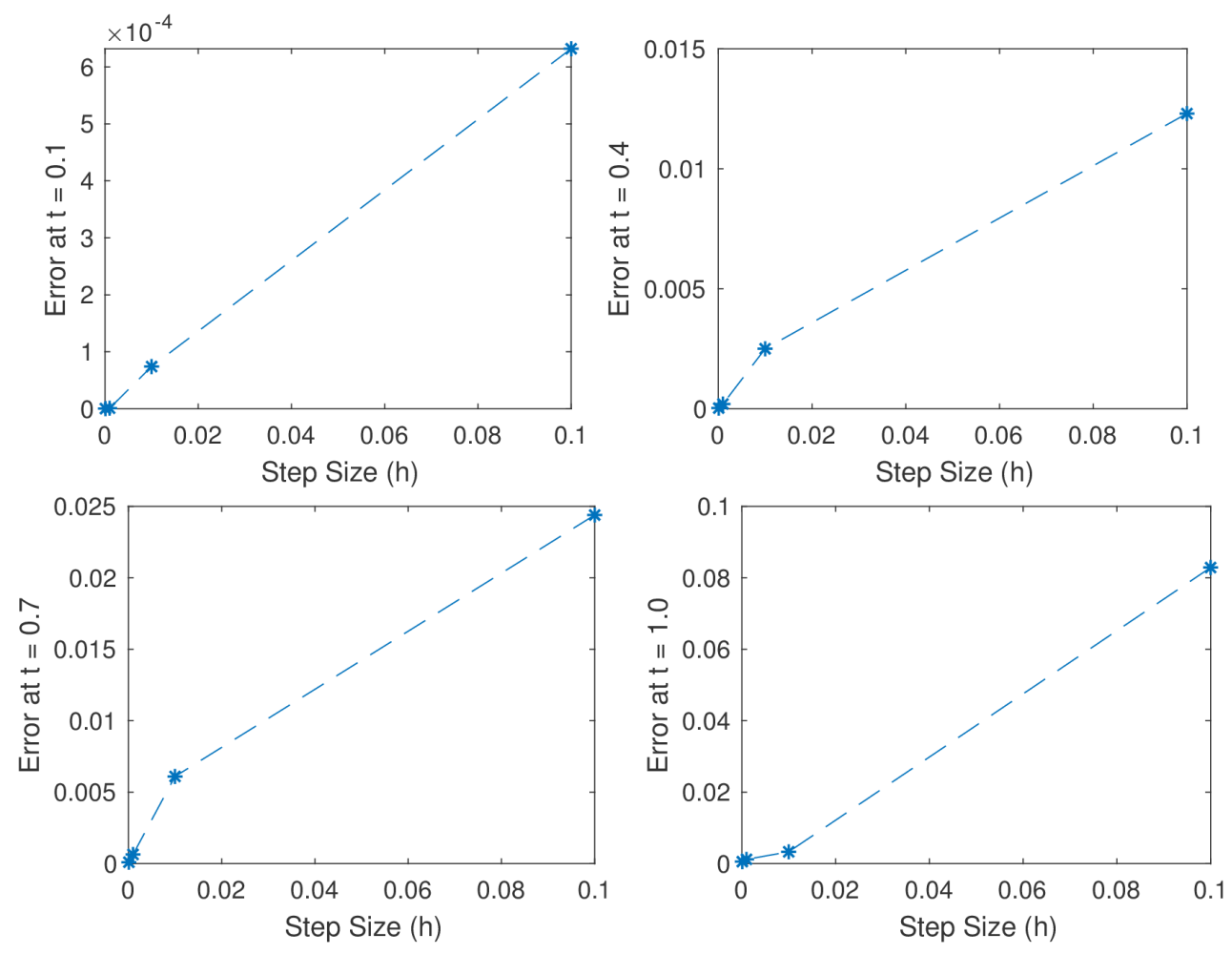

Figure 2. Error measured as the difference between the exact solution and the numerical solution at particular points in time between 0 and 1 . Step sizes used vary from $h=0.1$ down to $h=0.0001$

Finally, let us have a look at the mean-square errors of the numerical scheme offered in the previous section. Fig. 2 illustrates the point wise mean-square errors at various times between $t=0$ and $t=1$ of the numerical scheme for the initial values $x_{0}=0, y_{0}=0$, and the parameters $\nu=0.05, \sigma=1$ and $M=10,000$. The step size $h$ ranges from 0.1 down to 0.0001 . We observe a first order of convergence both in the position and in the velocity. This is the same mean-square order of convergence as the one offered in [15]. For the plots the log scale has been avoided intentionally. To emphasize the order $|h|$ convergence the original cale has been kept and the almost straight lines are observed as a result. Of course, these error terms are only for some specific values of $t$, for more detailed values for the error terms please also see Table 1.

\section{Conclusion}

In this study, a new explicit numerical scheme has been constructed for a specific Langevintype equation. The main mathematical tool behind this construction is the variation-of-constants formulation. The convergence rate for one step has been established to be $3 / 2$ for the linear Langevintype equation. As a result of this, the convergence rate at any step has established to be of order 1 . In the main theorem of the paper, Theorem 1, the upper bounds for the convergence analysis depend on the upper limit of the time interval, $T$. In a later corollary, these upper bounds have been updated to versions that are also independent of the the upper limit of the time interval, $T$. 
The proposed numerical scheme have been applied to the non-linear version of the Langevin-type equation. The theoretical results that have been proven for the linear case have been verified also by the non-linear case numerically. The stability of the numerical scheme has been shown numerically and graphically. Similar results have been obtained in the literature, but with semi-implicit numerical schemes. Just as strong results have been provided with explicit and easy to implement numerical difference equations. All of the numerical experiments have been in line with the existing literature, and occasional extensions, such as the stability of the velocity term, have been provided.

\section{References}

1 Langevin P. On the theory of Brownian motion / P. Langevin // C.R. Acad. Sci. - 1908. - 146. - P. 530-533.

2 Zwanzig R. Nonequilibrium Statistical Mechanics / R. Zwanzig. - Oxford University Press, New York, 2001.

3 Kubo R. The fluctuation-dissipation theorem / R. Kubo // Reports on Progress in Physics. 1966. - 29. - P. 255-284.

4 Kubo R. Statistical Physics II Nonequilibrium Statistical Mechanics / R. Kubo, M. Toda, N. Hashitsume. - Springer, Berlin, Heidelberg, 1991.

5 Sekimoto K. Langevin equation and thermodynamics / K. Sekimoto // Progress of Theoretical Physics Supplement. - 1998. - 130. - P. 17-27.

6 Kostin M.D. On the Schrödinger-Langevin equation / M.D. Kostin // Journal of Chemical Physics. - 1972. - 57. - No. 9. - P. 35-89.

7 Gillespie D.T. The chemical Langevin equation / D.T. Gillespie // Journal of Chemical Physics. - 2000. - 113. - No.1. - P. 1-10.

8 Diomande B. Multivalued stochastic delay differential equations and related stochastic control problems / B. Diomande, L. Maticiuc // Quaestiones Mathematicae. - 2017. - 40. - No. 6. P. $769-802$.

9 Nie D. Direct numerical simulation of particle Brownian motion in a fluid with inhomogeneous temperature field / D. Nie, C. Wang // Thermal Science. - 2019. - 0. - No. 0. - P. 98-98.

10 Higham D. J. An algorithmic introduction to numerical simulation of stochastic differential equations / D.J. Higham // SIAM Reviews. - 2001. - 43. - P. 525-546.

11 Shoji I. A note on convergence rate of a linearization method for the discretization of stochastic differential equations / I. Shoji // Communications inNonlinear Science and Numerical Simulation. - 2011. - 16. - No. 7. - P. 2667-2671.

12 Jiang F. A note on order of convergence of numerical method for neutral stochastic functional differential equations / F. Jiang, Y. Shen, F. Wu // Communications in Nonlinear Science and Numerical Simulation. - 2012. - 17. - No. 3. - P. 1194-1200.

13 Wang W. Analysis of a few numerical integration methods for the Langevin equation / W. Wang, R.D. Skeel // Molecular Physics. - 2003. - 101. - No. 14. - P. 2149-2156.

14 Izgi B. Milstein-type semi-implicit split-step numerical methods for non-linear stochastic differential equations with locally Lipschitz drift terms / B. Izgi, C. Cetin // Thermal Science. 2019. - 23. - No. 1. - P. S1-S12.

15 Cohen D. On the numerical discretisation of stochastic oscillators / D. Cohen // Mathematics and Computers in Simulation. - 2012. - 82. - P. 1478-1495.

16 Milstein G. N. Stochastic Numerics for Mathematcal Physics / G.N. Milstein, M.V. Tretyakov. - Springer-Verlag, Berlin, 2004. 
М. Акат, Р. Кошкер, А. Сирма

\title{
Ланжевен типті теңдеуінің сандық схемасы туралы
}

\begin{abstract}
Мақалада Ланжевен типті сандық теңдеулері үшін тұрақтыны варияциялау формуласына негізделген сандық тәсілі ұсынылған. Сызықты және сызықты емес жағдайлары жеке қарастырылған. Жинақты болуының дәлелдеуі сызықты жағдай үшін көрсетілген, ал сандық есептеуі сызықты емес жағдай үшін орындалған. Сандық схема үшін, бірінші ретті жинақтылығы теориялық және сандық түрде көрсетілген. Сандық схеманың орнықтылығы сандық түрде көрсетілген және графикалық түрде бейнеленген.
\end{abstract}

Kiлm сөздер: айырымдық схемасы, стохастикалық осцилляторлары, Ланжевен теңдеуі, тұрақты вариациясы.

\author{
М. Акат, Р. Кошкер, А. Сирма
}

\section{О численных схемах для уравнений типа Ланжевена}

В статье предложен численный подход, основанный на формуле вариации констант для численных уравнений дискретизации типа Ланжевена. Линейные и нелинейные случаи рассмотрены отдельно. Доказательства сходимости были предоставлены для линейного случая, а численная реализация выполнена для нелинейного случая. Сходимость первого порядка для численной схемы показана теоретически и численно. Устойчивость численной схемы показана численно и изображена графически.

Ключевые слова: разностные схемы, стохастические осцилляторы, уравнение Ланжевена, вариация постоянных.

\section{References}

1 Langevin, P. (1908). On the theory of Brownian motion. C.R.Acad.Sci., 146, 530-533.

2 Zwanzig R. (2001). Nonequilibrium Statistical Mechanics. Oxford University Press, New York.

3 Kubo R. (1966). The fluctuation-dissipation theorem. Reports on Progress in Physics, 29, 255284.

4 Kubo R., Toda, M., \& Hashitsume, N. (1991). Statistical Physics II Nonequilibrium Statistical Mechanics. Springer, Berlin, Heidelberg.

5 Sekimoto, K. (1998) Langevin equation and thermodynamics. Progress of Theoretical Physics Supplement, 130, 17-27.

6 Kostin, M. D. (1972). On the Schrödinger-Langevin equation. Journal of Chemical Physics, 57, 9, 35-89.

7 Gillespie, D.T. (2000). The chemical Langevin equation. Journal of Chemical Physics, 113, 1, $1-10$.

8 Diomande, B., \& Maticiuc, L. (2017). Multivalued stochastic delay differential equations and related stochastic control problems. Quaestiones Mathematicae, 40, 6, 769-802.

9 Nie, D., \& Wang, C. (2019). Direct numerical simulation of particle Brownian motion in a fluid with inhomogeneous temperature field. Thermal Science, 0,0, 98-98.

10 Higham D. J. (2001). An algorithmic introduction to numerical simulation of stochastic differential equations. SIAM Reviews, 43, 525-546.

11 Shoji I. (2011). A note on convergence rate of a linearization method for the discretization of stochastic differential equations. Communications in Nonlinear Science and Numerical Simulation, $16,7,2667-2671$. 
12 Jiang F., Shen, Y., \& Wu, F. (2012). A note on order of convergence of numerical method for neutral stochastic functional differential equations. Communications in Nonlinear Science and Numerical Simulation, 17, 3, 1194-1200.

13 Wang, W. Analysis of a few numerical integration methods for the Langevin equation. Molecular Physics, 101, 14, 2149-2156.

14 Izgi, B., Cetin, C. (2019). Milstein-type semi-implicit split-step numerical methods for non-linear stochastic differential equations with locally Lipschitz drift terms. Thermal Science, 23, 1, 1-12.

15 Cohen, D. (2012). On the numerical discretisation of stochastic oscillators. Mathematics and Computers in Simulation, 82, 1478-1495.

16 Milstein, G. N., \& Tretyakov, M. V. (2004). Stochastic Numerics for Mathematcal Physics. Springer-Verlag, Berlin. 